\title{
Cripto: roles in mammary cell growth, survival, differentiation and transformation
}

\author{
Christina C. Niemeyer ${ }^{1,4}$, M. Graziella Persico ${ }^{2}$ and \\ Eileen D. Adamson ${ }^{1,3}$ \\ 1 The Burnham Institute, La Jolla Cancer Research Center, 10901 North Torrey \\ Pines Road, La Jolla, California 92037, USA \\ ${ }^{2}$ International Institute Genetics and Biophysics, Naples, Italy \\ ${ }^{3}$ corresponding author: Eileen Adamson. tel: (619) 455-6480; fax: (619) 646- \\ 3195; e-mail: eadamson@ljcrf.edu \\ ${ }^{4}$ Present address: Structural Bioinformatics Inc., 10929 Technology Place, \\ San Diego. 92127, USA
}

Received 28.5.97; revised 17.11.97 accepted 5.1.98

Edited by D. Green

\begin{abstract}
Cripto-1 (Cr-1) protein, encoded by the teratocarcinomaderived growth factor gene (TDGF-1), is highly correlated with transformation in breast cancer. Eighty-two percent of breast carcinomas express $\mathrm{Cr}-1$ whereas it is undetected in normal human breast tissue. We confirmed and extended findings that $\mathrm{Cr}-1$ protein is expressed during the pregnancy and lactating stages of normal murine mammary glands but is barely detectable in glands from virgin animals and is undetectable in involuted glands. Cr-1 was found to be expressed in CID 9 cells, a line of mammary epithelial cells derived from 14.5 day pregnant mice and we have used these cells to investigate the roles of this gene. Exogenous mouse Cr-1 expression from a retroviral vector caused CID 9 cells to grow at an increased rate and to increased cell densities compared to parental and control cells. CID 9 cells overexpressing $\mathrm{Cr}-1$ did not differentiate efficiently. Infection of CID 9 cells with a $\mathrm{Cr}-1$ antisense vector caused these cells to change in morphology, to grow slowly, to undergo apoptosis at a higher rate and to achieve lower saturation densities but the cells were still capable of differentiating. We concluded that $\mathrm{Cr}-1$ is an autocrine growth factor for normal breast cells, that when over-expressed stimulates excessive cell proliferation at the expense of differentiation. In transplantation studies, Cr-1 over-expression stimulated the growth and survival of mammary cells, but did not stimulate tumorigenesis in vivo.
\end{abstract}

Keywords: retroviruses; overexpression; antisense; milk proteins; apoptosis; anchorage independent growth; tumorigenicity

Abbreviations: $\mathrm{Cr}-1$ or CR-1, Cripto; DMEM, Dulbeccos minimum essential medium; EGF, epidermal growth factor; ECL, enhanced chemiluminescence; ELISA, enzyme-linked immunosorbant assay; FBS, fetal bovine serum; IRES, internal ribosome entry site, PBS, phosphate-buffered saline; TDGF-1, teratocarcinoma derived growth factor-1 gene

\section{Introduction}

Cripto (Cr-1) was first assigned to the Epidermal Growth Factor (EGF)-like family of ligands that includes transforming growth factor-alpha (TGF $\alpha$ ), and amphiregulin (AR). This family of proteins contain 'EGF-like domains' with a highly conserved structure of three disulfide loops, and in $\mathrm{Cr}-1$, the six conserved cysteines that make up the EGF motif lacks the A-loop and the B-loop is truncated. As a result, Cr-1 does not bind to the EGFR or members of the ErbB family of receptors. At the carboxyterminus of $\mathrm{Cr}-1$, an additional six-cysteine motif is present that is conserved in an analogous protein recently isolated from Xenopus laevis (Kinoshita et al, 1995). A related mouse protein, Cryptic, was recently cloned and this group of genes forms a new family named CFC (Shen et al, 1997). Mouse Cr-1 protein consists of 171 amino acids and unlike the human CR-1 (188 amino acids) has a signal sequence and is secreted (Brandt et al, 1994) (Dono et al, 1993) (Normanno et al, 1994) (Ciccodicola et al, 1989).

CR-1 was cloned as a full length isolate from a CDNA library derived from the human teratocarcinoma cell line NTERA2 clone D1. The TDGF-1 (CR-1) gene and an intronless sequence CR-3 were isolated and mapped on human chromosomes 3 and $\mathrm{X}$, respectively (Dono et al, 1991; Saccone et al, 1995). Mouse Tdgf1 (encoding Cr-1), and two intronless pseudogenes, Tdgf2 and Tdgf3, have been isolated and characterized (Dono et al, 1993; Liguori et al, 1996). Mouse $\mathrm{Cr}-1$ has $93 \%$ similarity to its human counterpart in the EGF-like domain, which is the most conserved. The molecular mass of Cripto protein varies according to the species and cell type: in human GEO colon and NTERA2/D1 embryonal carcinoma cells a polypeptide of $36 \mathrm{kDa}$ predominates and it can be differently processed by glycosylation or modified in other ways. In mouse F9 cells only the secreted protein has been analyzed and a single species at $24 \mathrm{kDa}$ was noted (Brandt et al, 1994).

CR-1 protein is highly correlated with tumorigenicity. Of 68 biopsies on breast carcinomas, $82 \%$ expressed Cripto. Cripto expression has not been detected in normal human breast tissue or cell lines (Qi et al, 1994). Growth of two human breast carcinoma cell lines and the nontransformed human epithelial cell line 184A1N4 was stimulated by the addition of synthetic refolded human CR-1 peptides containing the EGF-like domain (Brandt et al, 1994). All the human mammary tumor cell lines examined were found to express CR-1 using RT-PCR, Northern blot analysis and immunocytochemistry (Normanno et al, 1994). The human CR-1 cDNA has been overexpressed in mouse NIH3T3 cells and was shown to transform these cells such that they grew in soft agar in contrast to control cells 
(Ciccodicola et al, 1989). The same construct transformed an immortal mouse mammary cell line, NOG-8 (Ciccodicola et al, 1989). Mammary tumors formed in transgenic mice overexpressing oncogenes TGF $\alpha$, neu, int-3, polyomavirus middle $\mathrm{T}$ antigen or simian virus 40 large $\mathrm{T}$ antigen, all express Cripto-1 (Kenney et al, 1995). In addition, Cr-1 expression was observed in pregnant and lactating mouse mammary glands (Kenney et al, 1995). The latter observation suggested that Cripto played a role in differentiation as well as proliferation.

In the present study, CID 9 cells were used to examine the expression of Cripto-1 and to determine the effects of over- and under-expression of this growth factor during growth versus differentiation. CID 9 cells are a subpopulation (Schmidhauser et al, 1990) of the COMMA-1D mammary epithelial cell line which was established from normal 14.5 day pregnant Balb/c mouse mammary gland tissue. They retain important characteristics of normal morphogenesis and functional differentiation in vitro (Danielson et al, 1984). Normal CID 9 cells differentiate into alveolar-like structures (mammospheres) that express $\beta$-casein when grown on a laminin-rich extracellular matrix in the absence of fetal bovine serum (FBS) and in the presence of lactogenic hormones (Schmidhauser et al, 1990).

We show here that $\mathrm{Cr}-1$ is differentially expressed during mammary gland development and is expressed in a hormone dependent fashion in the normal mammary epithelial cell line. Inhibition of $\mathrm{Cr}-1$ expression caused a change in cell morphology, decreased cell growth, increased programmed cell death and reduced anchorage independent growth. Mouse $\mathrm{Cr}-1$ overexpression stimulated anchorage dependent and independent cell growth and decreased the differentiation potential of the mammary cells. However, no increases in the tumorigenicity of $\mathrm{Cr}-1$ over-expressing mammary cells were noted after transplantation into syngeneic hosts.

\section{Results \\ Cripto is a pregnancy and lactation stage specific protein}

Cripto protein, Mr 24 and $26 \mathrm{kDa}$, is strongly expressed in the second phase of mammary gland development, pregnancy (Figure 1, lane 2 shows $\mathrm{Cr}-1$ in 14.5 day pregnant glands). This implies that its expression is driven by pregnancyassociated hormones, since involution of mammary gland tissue after pregnancy is associated with loss of Cripto expression (Figure 1, lane 4). In contrast, the virgin mouse mammary gland expresses extremely low levels (Figure 1, lane 1) in partial agreement with Kenney et al. (1995).

$\mathrm{Cr}-1$ is also expressed in CID 9 cells, derived from 14.5 day pregnant mammary glands, as a $24 \mathrm{kDa}$ protein (Figure 1, lane 7). When the cells were cultured on basement membrane substrates, they differentiated, observed as mammosphere and expression of casein, and they also expressed higher levels of $\mathrm{Cr}-1$ protein. The $\mathrm{Cr}-1$ protein was also modified to $\mathrm{Mr} 26$ and $28 \mathrm{kDa}$ forms (Figure 1, lane 6). The CID 9 mammosphere structures appeared to be functionally similar to the in vivo pregnant-lactating mammary gland with stage-specific Cripto gene expression. This observation prompted us to test the role of $\mathrm{Cr}-1$ by experimental manipulation of $\mathrm{C}-1$ expression in CID 9 cells.

\section{Expression of exogenous Cripto}

In order to affect the expression of Cripto in mammary cells, a retroviral vector containing either sense or antisense Cripto was constructed. The polycistronic retroviral vector pGCEN (Figure 2) contains the encephalomyocarditis virus internal ribosome entry site (IRES) which allows efficient expression of multiple genes from a single proviral genome. Transcriptional controls and RNA processing steps that differentially affect expression of the exogenous genes can be avoided (Ghattas et al, 1991). Cripto cDNA sequences (both sense and antisense) were inserted as described in the Materials and Methods section. Cripto cDNA and the selectable marker, neo $^{r}$ are both expressed from a single promoter using the EMCV IRES insert. The pGCEN vector LTR is a promoter known to function in the mammary gland (Bradbury et al, 1991). CID 9 cells were infected with the retroviruses. Because the CID 9 cells are a heterogeneous cell

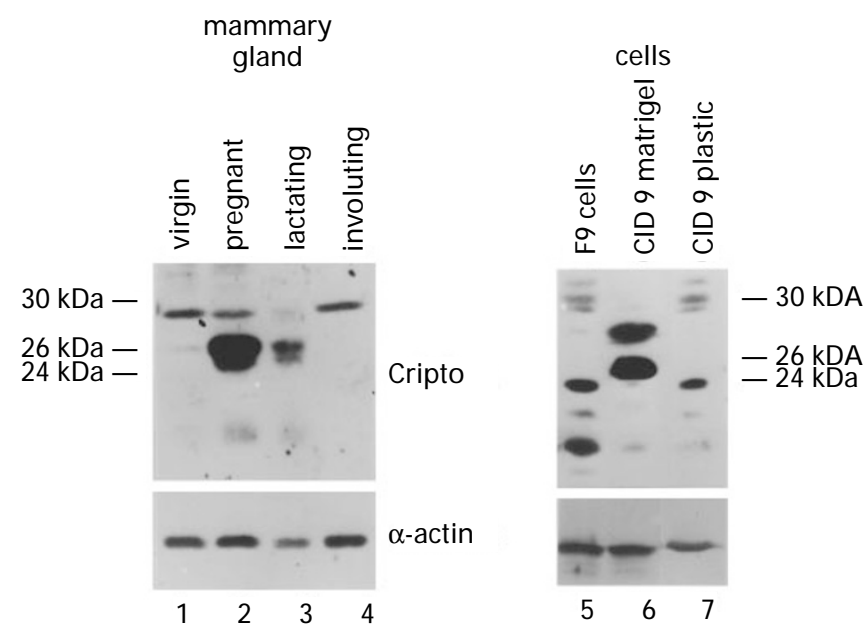

Figure 1 Immunoblots of normal mammary gland tissue and cells to show Cripto protein expression. Cripto is highly expressed as 24 and $26 \mathrm{kDa}$ proteins in 14.5 day pregnant gland (lane 2) and at a lower level at the lactating stage (lane 3 ) of mammary gland development. It is expressed at very low levels in virgin glands (lane 1) and is not seen in involuting glands (lane 4). Cripto is expressed as a $24 \mathrm{kDa}$ protein in undifferentiated F9 cells (lane 5) and as both 26 and $28 \mathrm{kDa}$ proteins in CID 9 cells grown on an extracellular matrix (Matrigel) for 7 days in the presence of lactogenic hormones (lane 6), compared to CID 9 cells grown in maintenance media on plastic (lane 7). Other bands in the figure are non-specific bands

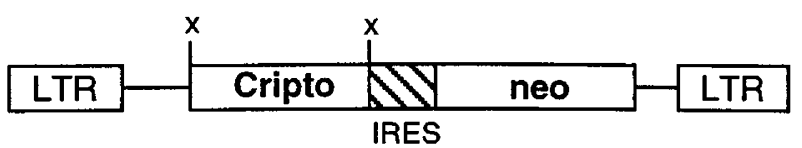

Figure 2 pGCEN retroviral expression vector used to over and under express Cripto in mammary cells. The Cripto cDNA was inserted in both orientations at the $\mathrm{Xhol}$ site $(\mathrm{X})$. IRES, encephalomyocarditis virus internal ribosome entry site; LTR, Moloney murine leukemia virus Long Terminal Repeat sequences; neo, bacterial neomycin resistance gene 
population, more than 250 clones were selected in G418 and then pooled.

The level of Cripto protein expression in the infected cells was measured using Western blot analysis. Two different populations of CID 9 cells containing Cripto in the sense orientation were analyzed (Figure 3) and showed that Cripto was overexpressed at levels greater than twofold higher than control vector populations (Figure 3). In the antisense populations only approximately onequarter of the amount of Cripto was expressed compared to the controls (Figure 3). Thus, the retroviral vector constructs effectively modulated $\mathrm{Cr}-1$ expression in CID 9 cells. Both cytokeratin positive and vimentin positive cells were observed, using indirect immunofluorescent staining, in all the populations. The proportion of keratin-positive cells was similar in all three populations, amounting to $55 \pm 10 \%$. Thus, there was no selection of one population and all the cell lines contained the two distinct cell types described by Desprez (Desprez et al, 1993).

\section{Morphology}

Monolayer cultures of CID 9 cells commonly show two cellular morphologies, a spindle-shaped and a typical epithelial

$\mathbf{A}$

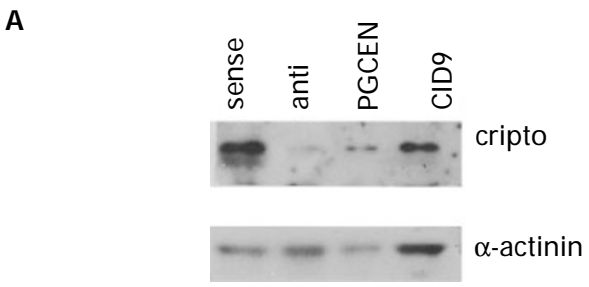

B

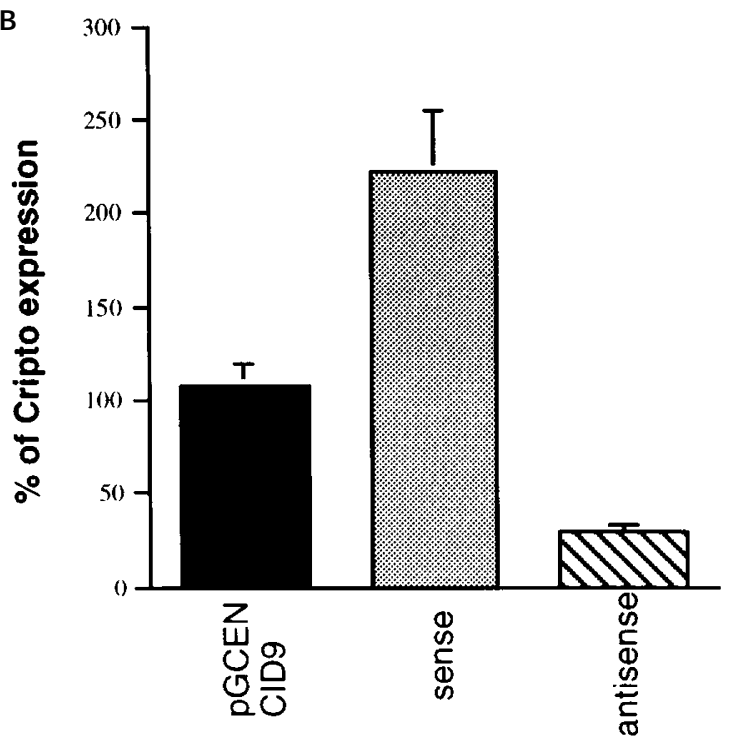

Figure 3 Cripto expression levels in infected CID 9 cells. (A) Overexpression of Cripto in CID 9 cells infected with the pGCEN-sense Cripto vector (sense) and underexpression in cells infected with the $\mathrm{pGCEN}$-antisense Cripto vecto (anti). $\alpha$-Actinin was used to show relative protein levels in each lane. (B) Graph of the percentage of Cripto expression \pm S.D. in two different populations of infected cells compared to control pGCEN vector infected CID 9 cells ( $p G C E N$ ) or uninfected CID 9 cells (CID 9) which was defined as $100 \%$ cobblestone pattern (Figure 4A). No differences were observed in the mixed morphology of cells after infection with the empty vector compared to uninfected CID 9 cells (Figure 4A and B). The cells infected with the sense Cripto cDNA also exhibited the same cellular morphology as the CID 9 cells or the pGCEN control CID 9 cells at both high and low cell densities. No significant morphological differences were observed during continuous propagation of these various pools. At low density, cells grew as islands of cells. In cultures remaining at confluence for 2 days, the presence of domelike structures was apparent. Cr-1 overexpressing cells formed more frequent and larger domelike structures (Figure 4C) compared to wt cells. Cells expressing antisense Cripto became morphologically distinct; the individual cells were flatter and spread to a larger area at both high and low density. They showed the more typical cobblestone morphology of epithelial cells (Figure 4D) and at confluence, they did not form domes. However, like the parental cells, they still contained at least two cell types that expressed keratin or vimentin intermediate filaments (Desprez et al, 1993), and did not represent a specifically selected population.

\section{Cell proliferation and apoptosis}

To determine if over- and under-expression of $\mathrm{Cr}-1$ had an effect on mammary cell growth, several types of growth assays were performed. Cell growth rates were determined using maintenance culture medium. In this media, the CID 9 cells overexpressing Cripto (sense), underexpressing Cripto (antisense), and the control cells containing the empty vector (pGCEN) all grew at approximately the same rate for the first $24 \mathrm{~h}$. Then the cells overexpressing Cripto grew faster so that at 48 and $72 \mathrm{~h}$ there were a greater number of cells compared to the control. The cells with reduced Cripto appeared to reach confluence by $24 \mathrm{~h}$ and the level of cells subsequently decreased after $48 \mathrm{~h}$ suggesting that they were starting to die (Figure 5A).
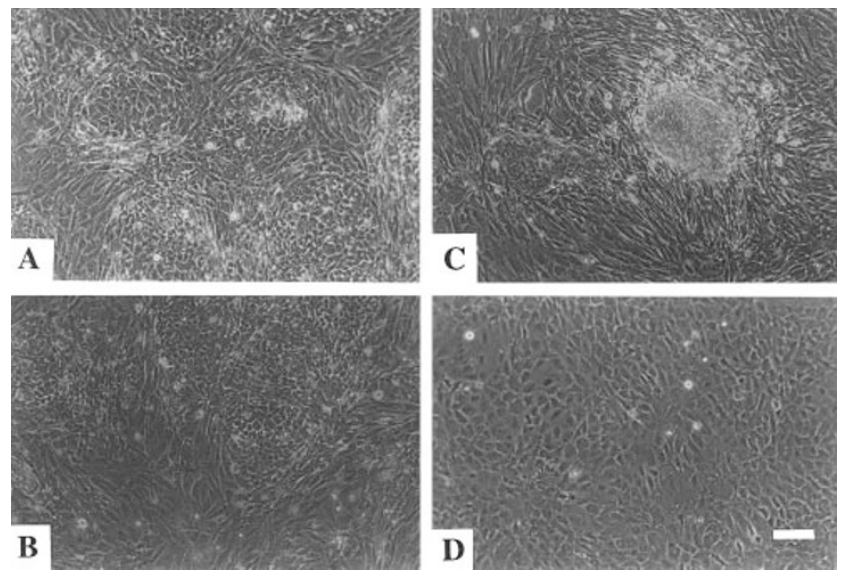

Figure 4 Morphological effect of Cripto over-and under-expression on CID 9 cells. Phase contrast micrographs compare the general appearance of the (A) normal CID 9 cells with (B) cells infected with control pGCEN vector, and (C) cells infected with the Cripto expression vector, and (D) cells infected with the antisense Cripto expression vector. All the cells were seeded at the same density and allowed to grow the same length of time. For all panels the bar indicates $100 \mu \mathrm{m}$ 


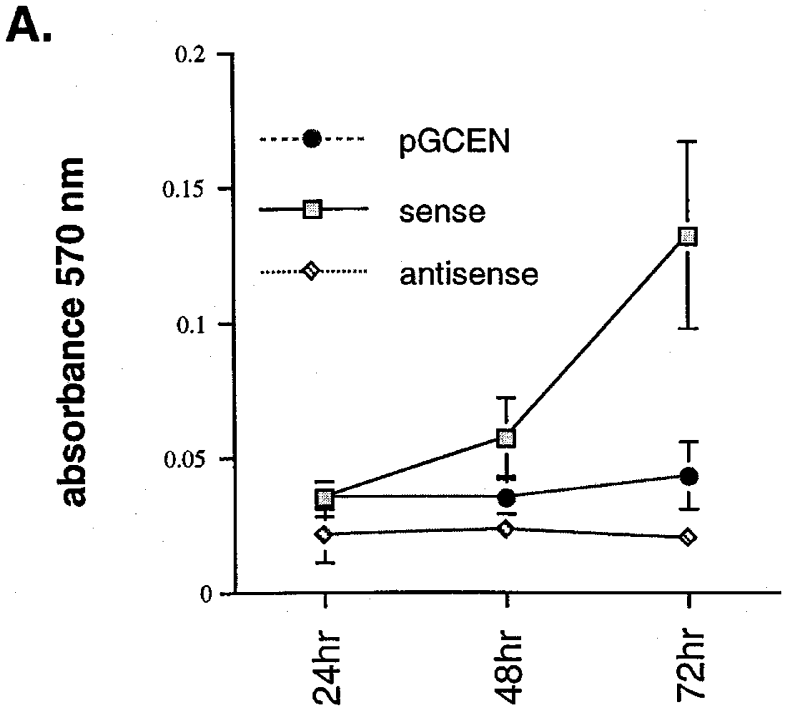

B.

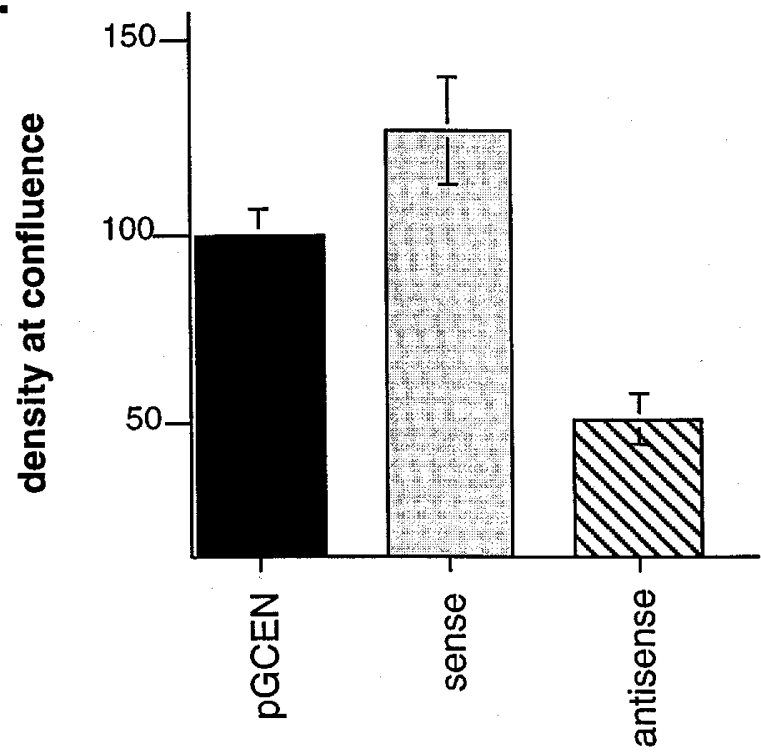

Figure 5 Cell growth assays. Growth rates of CID 9 cells containing the empty vector ( $p G C E N)$, the Cr-1 expression vector (sense), and the antisense $\mathrm{Cr}-1$ expression vector (antisense). (A) The absorbance at $570 \mathrm{~nm}$ is directly proportional to the number of cells/well. (B) Plateau growth density of cells expressing various levels of $\mathrm{Cr}-1$. Values are expressed as a percentage of the CID 9 cells containing the control pGCEN vector. Bars, S.D.

To determine cell densities at confluence, cells were grown in $2 \%$ fetal bovine serum (FBS), allowed to grow for 5 days and remain at confluence for 2 days and then counted (Figure $5 \mathrm{~B}$ ). The $\mathrm{Cr}-1$ overexpressing cells grew to a greater density $\left(3.2 \times 10^{5}\right.$ cells $\left./ \mathrm{cm}^{2}\right)$ than the control cells $\left(2.4 \times 10^{5}\right.$ cells $\left./ \mathrm{cm}^{2}\right)$. For CID 9 cells expressing decreased levels of $\mathrm{Cr}-1$, the density at confluence remained at $1.2 \times 10^{5}$ cells $/ \mathrm{cm}^{2}$. Thus the cells containing the antisense vector showed contact inhibition at a statistically significant $(P<0.05)$ lower cell density compared to parental and control cells.
To determine if $\mathrm{Cr}-1$ lowered the requirement of CID 9 cells for growth factors, cell proliferation assays were also performed by plating the cells in media containing $2 \%$ FBS to allow attachment and then growing them in serum-free conditions. Uninfected CID 9 cells and cells containing the sense or empty vector grew at approximately the same rate and all the rates were lower than in $2 \%$ or $5 \%$ FBS conditions. The CID 9 cells containing the retrovirus with $\mathrm{Cr}-1$ in the antisense orientation showed no growth in serum-free media and after several days no cells survived (data not shown).

This observation suggested that the loss of $\mathrm{Cr}-1$ expression might affect survival of cells even in serumcontaining cultures and this was tested next. Apoptosis levels were assessed by nuclear morphology and by TUNEL assays (Figure 6a). Numbers of apoptotic nuclei (Figure 6b) in log phase CID 9 cells were $0.60 \% \pm 0.20$ of the population in control pGCEN cells; this rate decreased to $0.28 \% \pm 0.16(P<0.05)$ in Cripto overexpressing cells and increased to $1.53 \% \pm 0.66(P=0.035)$ in antisense cells. More frequent apoptotic nuclei were observed in antisenseexpressing cells (Figure 6a, E, F) than in either of the other two cell populations (Figure 6a, A, B, C, D). The expression of Cripto therefore endows a growth advantage as well as better survival in cultured mammary cells.

\section{Colony formation and anchorage independent growth}

The Cripto overexpressing sense CID 9 cells have a greater tendency to build up multilayers of cells in monolayer cultures compared to control pGCEN infected or uninfected CID 9 cells (Figure 7A and $B$ ). The normal cells formed colony-like domes but CID 9 cells underexpressing $\mathrm{Cr}-1$, on the other hand, showed very little colony formation compared to control cells and ceased to proliferate after reaching confluence (Figure 7C). The three CID 9 populations showed differential abilities to grow in soft agar (Figure 7). Control cells formed 15 \pm 3 colonies per dish or $0.04 \%$ of the plated cells formed colonies (Figure 7D). Whereas the Cripto overexpressing cells formed greater than $79 \pm 6$ colonies or $0.2 \%$ of plated cells formed colonies (Figure 7E). The antisense cells did not grow in soft agar and were therefore anchorage dependent for growth (Figure 7F).

\section{Differentiation}

CID 9 cells differentiate efficiently on an extracellular matrix in the presence of lactogenic hormones. Our three populations, containing either the sense, antisense, or empty pGCEN vector, were allowed to differentiate on Matrigel ${ }^{\mathrm{TM}}$, where morphological differentiation can be observed by the ability to form polarized epithelial structures termed mammospheres. The empty pGCEN infected CID 9 cells appeared the same as the parental CID 9 cells in that they formed frequent mammosphere structures (Figure 8A). The CID 9 cells overexpressing $\mathrm{Cr}-1$ grew faster than the control cells (data not shown) and there were overlapping cell layers, however, no mammosphere structures formed (Figure $8 \mathrm{~B}$ ). This suggests that overexpression of $\mathrm{Cr}-1$ in cells overrides the 

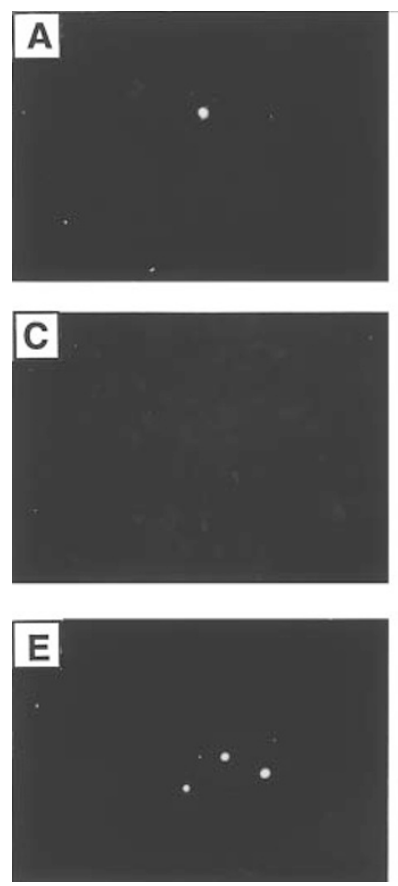
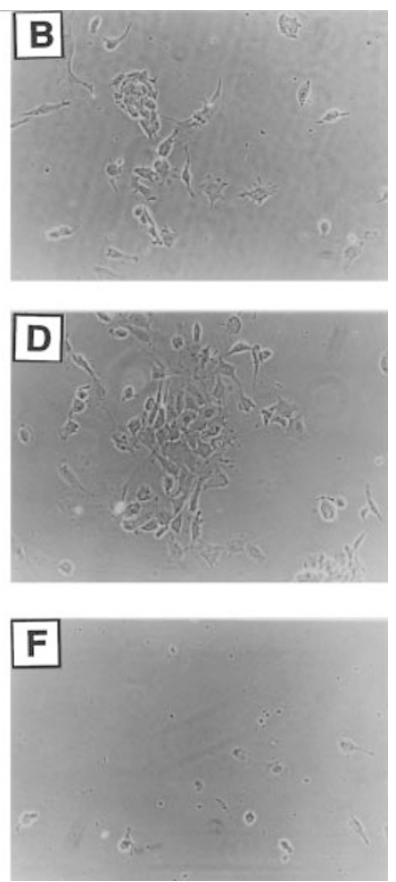

b

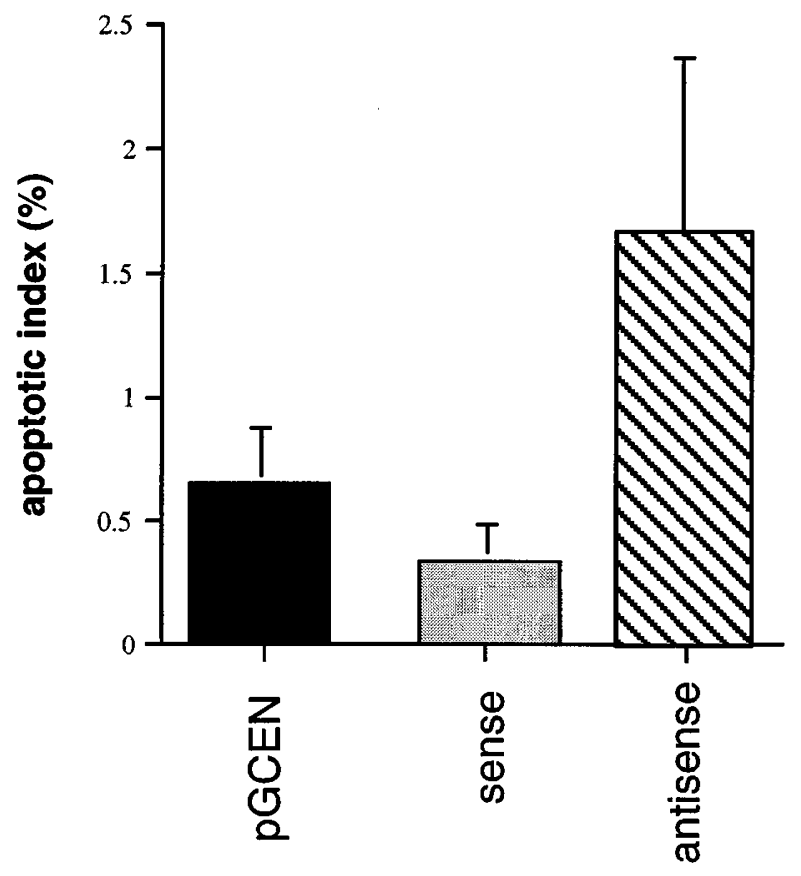

Figure 6 The effect of Cr-1 on CID9 cell survival. (a) In situ detection of apoptotic cells with the TUNEL method (left panels, A, C, E) and phase contrast microscopy (right panels, B, D, F) of CID 9 cells expressing various levels of $\mathrm{Cr}-1$. All cells were plated at the same density and grown under the same conditions. A, $\mathrm{B}$, control cells containing the empty pGCEN vector; C, D, CID9 cells overexpressing Cr-1 (sense); E, F, cells underexpressing Cr-1 (antisense). One representative field of each population is shown. (b) Apoptotic levels of log phase CID 9 populations (see Materials and Methods for details). Bars, S.D.

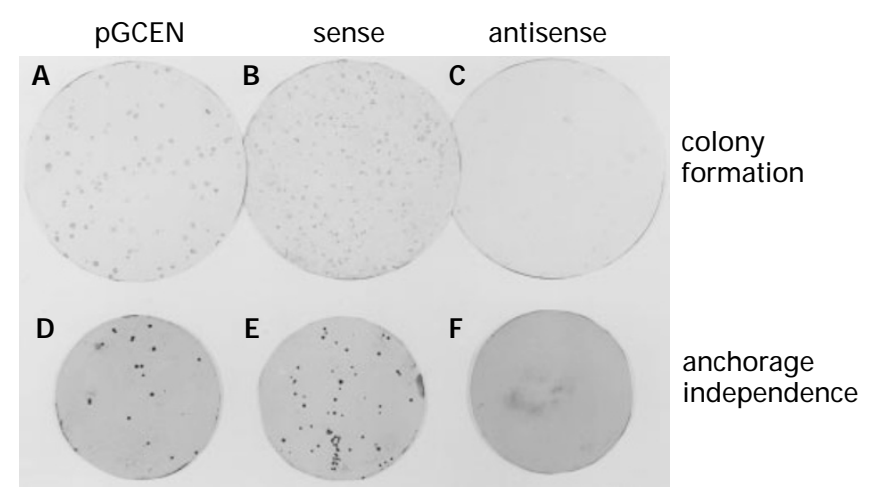

Figure 7 Colony formation in monolayer culture and anchorage independence (soft agar) assays of various populations. The CID 9 cells containing the empty vector ( $p$ GCEN) show some colonies formed both on plastic (A) and in soft agar (D). CID 9 cells overexpressing $\mathrm{Cr}-1$ (sense) show a threefold greater number of colonies both on plastic (B) and in soft agar (E). Whereas, CID 9 cells underexpressing $\mathrm{Cr}-1$ (antisense) show very little or no colony formation on plastic (C) or in soft agar (F)

signals leading to differentiation that normally appear. Interestingly, antisense expressing cells also did not form any mammospheres but tended to aggregate into aster-like structures (Figure 8C).

Biochemical indications for differentiation in mammary cells are the syntheses of milk proteins including $\beta$-casein. The CID 9 cells were grown in the presence of the lactogenic hormones, insulin, prolactin, and hydrocortisone either on an extracellular matrix or on plastic, and $\beta$-casein was detected by immunoblotting with an antibody to mouse milk proteins. Equal loading of gels was verified by immunoblotting with an antibody to $\alpha$-actinin (Figure 9 , lower panel) and the levels of $\mathrm{Cr}-1$ produced in the cells collected after the experiment was confirmed by immunoblotting with anti-Cr-1 (Figure 9, upper panel). The CID 9 cells overexpressing $\mathrm{Cr}-1$ showed only about half the amount of $\beta$-casein expression compared to the control CID 9 population (Figure 9, lanes 2, 3, 11, and 12). This agrees with our morphological observations that $\mathrm{Cr}-1$ overexpressing cells are predominantly proliferating compared to the control or normal CID 9 cells. Unexpectedly, the antisense containing CID 9 cells showed equal or greater expression of $\beta$-casein compared to the control suggesting (a) that $\mathrm{Cr}-1$ is not involved in $\beta$-casein expression and (b) that mammospheres are not important for differentiated expression. The addition of matrix is not necessary for casein expression (Figure 9, lanes 10-12), probably because CID9 cells synthesized their own matrix during this time. All populations of CID 9 cells (sense, antisense or empty vector) if grown in maintenance media without hydrocortisone and prolactin, either to confluence or not, failed to express $\beta$-casein (Figure 9, lanes 4-9).

A milk protein of approximately $22 \mathrm{kDa}$ whose regulation was distinct from the control of $\beta$-casein expression (Marte et al, 1995a) was produced by the CID 9 cells. Unlike $\beta$ casein expression, this protein was expressed in the cells whether lactogenic hormones were present or not. This 

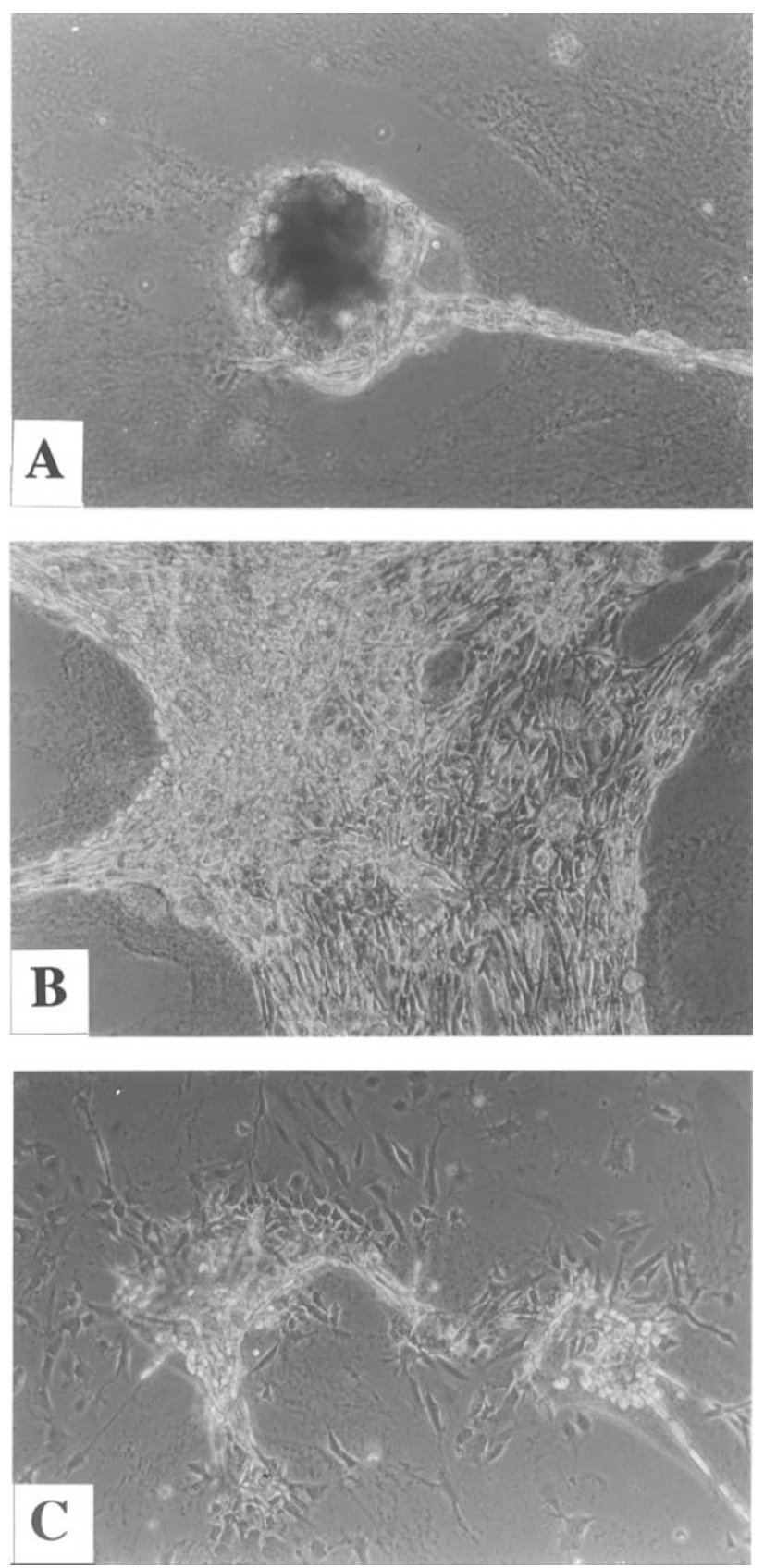

Figure 8 Morphological appearance of CID 9 cell populations grown on extracellular matrix (Matrigel) in the presence of lactogenic hormones. Phase contrast micrographs showing (A) normal differentiated structures (mammospheres) formed in control population of CID 9 cells containing the empty pGCEN vector, (B) overgrowth of CID 9 cells overexpressing $\mathrm{Cr}-1$, no mammosphere structures were observed and $(\mathbf{C})$ aster-like structures formed when decreased levels of Cripto were expressed. All the cells were seeded at the same density and allowed to grow for 6 days

protein was expressed at approximately the same level in all cell populations except Cr-1 overexpressing CID 9, which expressed only $15 \%$ of the level of expression of the $22 \mathrm{kDa}$ protein observed in the other populations (Figure 9, lane 2). This property further distinguished the $\mathrm{Cr}-1$ overexpressing cells.

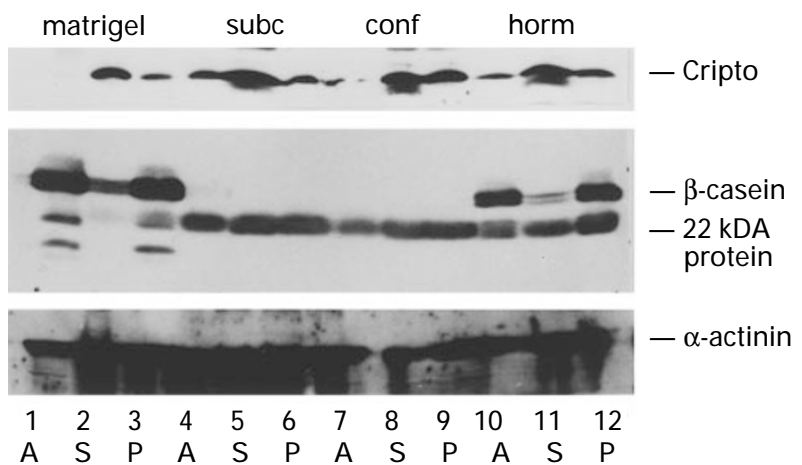

Figure 9 Immunoblots to show proteins produced by populations of CID 9 cells grown under various conditions. CID 9 cells underexpressing $\mathrm{Cr}-1$ (A), overexpressing $\mathrm{Cr}-1$ (S) or expressing normal levels of $\mathrm{Cr}-1$ and containing the empty vector (P) were analyzed. Growth conditions included growth on Matrigel in the presence of lactogenic hormones for 6 days (Matrigel, lanes 1$3)$; growth on plastic in normal maintenance media until they were still subconfluent for 3 days (subc, lanes 4-6); growth on plastic in normal maintenance media until they were confluent for 5 days (conf, lanes 7-9); and growth on plastic in the presence of lactogenic hormones for 6 days (horm, lanes 10-12). The top panel indicates the Cripto expression in the populations. In the middle panel to compare the differentiation of cell populations, the $26 \mathrm{kDa} \beta$-casein and the $22 \mathrm{kDa}$ milk proteins are indicated. $\alpha$ Actinin staining was used as a control for equal loading of protein in the bottom panel

\section{CID 9 cells in vivo}

To determine if the over- or under-expression of $\mathrm{Cr}-1$ had an effect on mammary gland development in vivo, we transferred CID 9 cells into the cleared fat pads of Balb/c mice. Unexpectedly, both $\mathrm{Cr}-1$ sense-infected and uninfected CID 9 cells formed tumors in the transgenic fat pads, 5 to 6 weeks after transfer. We also tested the tumorigenic potential of the antisense Cripto expressing CID 9 cells. They remained tumorigenic, giving rise to tumors 6 weeks after insertion into the mammary fat pad of syngeneic Balb/c mice. The tumor growth rates were similar and the cells were histologically indistinguishable. Control mammary glands that were sham operated remained normal. Western blot analysis showed that approximately one-fifth the amount of Cripto was expressed in the tumors formed from antisense Cr-1 CID 9 cells compared to the parental CID 9 cells (data not shown). Therefore loss of antisense effect could not explain the unchanged tumorigenic potential of the CID 9 cells in vivo. We concluded that CID 9 cells were tumorigenic for reasons not relevant to Cripto expression.

We therefore turned to the parental cell line of the CID 9 cells, Comma-1D cells, to perform the same study, predicting that these cells may not be tumorigenic. Although uninfected Comma-1D cells transferred to cleared mammary fat pads produced no tumors, they did form hyperplastic outgrowths at the injection site in agreement with previous studies (Aguilar-Cordova et al, 1991). Comma-1D cells infected with the empty pGCEN or with the Cripto-expressing vector also formed hyperplastic outgrowths of similar sizes in numerous cases for each cell line. In contrast, Comma-1D cells infected with antisense $\mathrm{Cr}-1$, were unable to grow in cleared fat pads, supporting 
the finding that loss of $\mathrm{Cr}-1$ decreases cell survival. This was retested in primary mammary cultures that were antisense Cr-1-infected and these also would not repopulate the cleared mammary fat pad, whereas uninfected cells would do so.

\section{Discussion}

The mammary gland is a highly complex system of interacting cell types. At birth, it contains at least three epithelial compartments: luminal epithelium, alveolar epithelium, and myoepithelium (Streuli et al, 1995). The mammary gland goes through four distinct postnatal developmental stages. Estrogen dependent ductal growth occurs from 5 to 8 weeks of age in the mouse when epithelial 'end buds' ramify from the nipple throughout the fatty mesenchyme creating a bush-like network of ducts. The onset of pregnancy initiates a second phase of extensive proliferation in which lobular-alveolar structures develop from the existing ductal system, in a process that is driven by pregnancy-induced hormones and estrogen (Nandi, 1958). It was from this stage that CID 9 cells were derived. The lobular system grows and differentiates to form alveoli in which milk protein synthesis occurs during lactation, the third phase of development. Following weaning of the young, the mammary gland undergoes extensive remodeling, leading to the loss of the alveolar structures, a process called involution involving large scale apoptosis (Strange et al, 1995). Each phase of mammary gland development requires a specific combination of systemic hormones that presumably activate different combinations of locally acting factors. Signaling molecules that have been implicated in local actions include members of the EGF, Wnt, FGF and TGF- $\beta$ families (Coleman and Daniel, 1990) (Snedeker et al, 1991). Each gene is expressed differentially during these developmental stages. We show here that $\mathrm{Cr}-1$ is one of this group of genes, being strongly active during pregnancy, less active in lactation and switched off during involution of the mammary gland after pregnancy. This suggests both that $\mathrm{Cr}-1$ expression is regulated by pregnancy hormones and that Cripto has a function during these stages of mammary gland development.

In this study we took advantage of a mammary cell subpopulation that mimics pregnant mammary glands in vivo. CID 9 cells allowed us to assay both growth and differentiation events in culture. We found that $\mathrm{Cr}-1$ was expressed at higher levels when cells were stimulated to grow and differentiate to lactogenic phenotypes (in the presence of lactogenic hormones and extracellular matrix), similar to pregnant glands in vivo (Figure 1). This strengthens the hypothesis that these hormones upregulate $\mathrm{Cr}-1$ expression as they do amphiregulin (Martinez-Lacaci et al, 1995) and TGF $\alpha$ (Kenney et al, 1993; Reddy et al, 1994) in mammary tissue.

Kenney et al. (1995) showed by RT-PCR, the presence of $\mathrm{Cr}-1$ mRNA in the virgin mouse mammary gland, although 24 or $26 \mathrm{kDa}$ proteins were not observed using an anti-human $\mathrm{Cr}-1$ antibody. We were able to detect low amounts of a $\mathrm{Cr}-1$ protein of $26 \mathrm{kDa}$ in virgin glands of 8 week and older mammary glands (Figure 1, lane 1) using a mouse-specific $\mathrm{Cr}-1$ antibody. Twenty-four $\mathrm{kDa}$ is the predicted and expected size of the mouse secreted Cripto protein, demonstrated by Brandt et al. (1994) to be authentic $\mathrm{Cr}-1$. In our analyses using immunoblotting of mammary gland tissues and cell lysates, we detected two Cr-1 proteins of 24 and $26 \mathrm{kDa}$ (Figure 1) which are likely glycosylated or myristylated differently (Brandt et al, 1994). $\mathrm{Cr}-1$ protein is expressed in undifferentiated F9 embryonal carcinoma (EC) cells as a protein of $24 \mathrm{kDa}$ (Figure 1, lane 5) but is down-regulated in differentiated F9 cells, in agreement with others (Ciccodicola et al, 1989). CID 9 cells differentiate in vitro and we showed that $\mathrm{Cr}-1$ has an inhibitory influence on differentiation. We demonstrated that proliferation increased and cell death decreased in CID 9 cells overexpressing $\mathrm{Cr}-1$. Two separate assays, mammosphere formation and milk protein expression, showed that overexpression of $\mathrm{Cr}-1$ led to decreased differentiation. In agreement with our data, a 47-mer, containing the EGF-like motif only of recombinant human CR-1 is able to stimulate proliferation and inhibit $\beta$-casein expression in mouse $\mathrm{HC} 11$ mammary epithelial cells (Kannan et al, 1997). It is generally accepted that proliferation rates are inversely related to differentiation, and we demonstrated here that Cr-1 stimulated the proliferation needed to bring the cells to the state required (equivalent to pregnancy) for differentiation (lactation) but inhibited the differentiation process itself.

We identified $\beta$-casein as a major product in differentiated CID 9 cells. Another milk protein of $22 \mathrm{kDa}$ was also observed to be regulated independently of $\beta$-casein, a finding similar to that of Marte et al, (1995b) in neuregulintreated $\mathrm{HC} 11$ cells which were also derived from COMMA1D cells. The $22 \mathrm{kDa}$ milk protein appeared to be specifically down regulated in CID 9 cells overexpressing $\mathrm{Cr}-1$ when grown on an extracellular matrix. The nature of this protein and the mechanism of its regulation remains unknown.

How does the evidence presented here fit with the suggestion that $\mathrm{Cr}-1$ is an oncogene? Cripto overexpression caused the cells to grow faster, to become less contact inhibited, allowed growth in domes, caused cells to survive clonal cell growth, and allowed anchorage independent growth (Figure 5, 6 and 7). Together these results suggest that $\mathrm{Cr}-1$ overexpression leads to a transformed phenotype in vitro that would characterize $\mathrm{Cr}$ 1 as an oncogene. Moreover, when $\mathrm{Cr}-1$ expression was reduced in cells that normally expressed it, they grew at one-third the rate of the control cells and became contact inhibited earlier and failed to grow anchorage independently or at clonal densities. This clearly suggests that $\mathrm{Cr}-1$ is an autocrine growth factor for CID 9 cells. Our data and the NOG-8 results (Ciardiello et al, 1991) support the hypothesis that overexpression of $\mathrm{Cr}-1$ leads to transformation and increased proliferation of normal mouse mammary epithelial cells. Our results also show that Cripto is required for normal growth and morphology of mammary cells during the pregnancy stage.

In contrast, in vivo tests do not lend support to a tumorigenic activity of $\mathrm{Cr}-1$ in mammary cells. Although CID 9 cells are an excellent model for 'normal' mammary epithelial cell growth and differentiation in vitro, they proved to be tumorigenic when transplanted into syngeneic cleared 
fat pads. In fact, control CID 9 cells (infected with empty vector) were able to grow in soft agar, suggesting they were already transformed. COMMA-1D cell studies were somewhat more revealing because when infected with the antisense $\mathrm{Cr}-1$ retroviruses, they were unable to grow at clonal densities, indicating that these cells are much more sensitive to apoptosis in the absence of $\mathrm{Cr}-1$. It is informative that NOG-8 mouse mammary cells even when over-expressing CR-1 do not form tumors in nude mice (Ciardiello et al, 1991), also suggesting that $\mathrm{Cr}-1$ is not a tumor-inducing gene.

Some questions about $\mathrm{Cr}-1$ need further study: What is the receptor for $\mathrm{Cr}-1$ in CID 9 cells? What is the precise role of $\mathrm{Cr}-1$ in human breast carcinoma, could $\mathrm{Cr}-1$ act as a survival factor that allows the cells to escape apoptotic signals? High expression of $\mathrm{Cr}-1$ in mouse and human embryonal carcinoma cells suggests that $\mathrm{Cr}-1$ could play a role in teratocarcinoma formation (Baldassarre et al, 1997).

In summary, the results suggest that $\mathrm{Cr}-1$ is positively regulated by lactogenic hormones and is important for mammary cell proliferation during the pregnancy stage of mammary gland development. Its function during pregnancy in the mammary gland may include differentiated cell renewal and survival but it is not directly involved in differentiation. Cr-1 also causes transformation in vitro and increases the rate of cell growth in mammary cells, a role suspected earlier because of its prevalent expression in breast and colon tumors. Using both in vitro and in vivo model systems we are addressing some of the questions concerning the regulation of $\mathrm{Cr}-1$ and more specifically its role in mammary gland development and cancer.

\section{Material and Methods}

\section{Cell culture}

CID 9 cells were kindly provided by Dr. Mina Bissell (Lawrence Berkeley Laboratory, Berkeley, CA). COMMA-1D cells were provided by Dr. Dan Medina (Baylor College of Medicine, Houston, TX). Cells were maintained in 1:1 DMEM: Hams F12 Nutrient Mixture (GIBCO BRL, Gaithersburg, MD) supplemented with $5 \%$ FBS and insulin $(5 \mu \mathrm{g} /$ $\mathrm{ml}$ ). For differentiation, the cells were grown for 7 days in the presence of lactogenic hormones (insulin $5 \mu \mathrm{g} / \mathrm{ml}$, hydrocortisone $1 \mu \mathrm{g} / \mathrm{ml}$, and prolactin $3 \mu \mathrm{g} / \mathrm{ml}$ ) on Matrigel (Collaborative Biomedical Products, Bedford, MA). The cells were plated in 1:1 DMEM:F12 Nutrient mixture, $2 \%$ fetal bovine serum (FBS), and lactogenic hormones at a density of $6 \times 10^{4}$ cells $/ \mathrm{cm}^{2}$. After $24 \mathrm{~h}$ the dishes were washed twice with PBS and fed with media containing no FBS but with lactogenic hormones.

Cell proliferation was quantified by determining formazan production from tetrazolium salt using the CellTiter 96 Non-Radioactive Cell Proliferation Assay (Promega, Madison, WI) and a ELISA plate reader programmed to quantify absorbance at $570 \mathrm{~nm}$ and background at $630 \mathrm{~nm}$. All assays were performed under conditions where the $570 \mathrm{~nm}$ absorbance readings were directly proportional to the number of cells/well. The anchorage independent growth assays were performed using a modification of a method described by Stoker et al, (1968). Cells were plated at a density of $4 \times 10^{4}$ cells per well of a 6 well plate in culture medium supplemented with $0.4 \%$ noble agar (Difco, Detroit, MI) over a lower layer of $0.3 \%$ agar, and allowed to grow for 21 days. Colonies were stained overnight with $0.05 \%$ piodonitrotetrazolium violet (Sigma Chemical Corp., St. Louis, MO), a vital stain that is taken up by mitochondria in cells.

Programmed cell death was quantified by (a) counting the the number of fragmented nuclei after staining logarithmically growing cultures with bisbenzamide (Sigma) and (b) in situ labeling of apoptosis induced DNA strand breaks (TUNEL assays) as described by the manufacturer (Boehringer Mannheim, Indianapolis, IN). Greater than 2000 cells were examined per assay and each assay was repeated twice. The results were combined to give the results in Figure $6 \mathrm{~B}$.

In these assays, statistical analysis in the Macintosh Excel program was applied, using the students two-tailed $t$ test.

\section{Infections}

The pGCEN vector was kindly provided by Dr. Richard Morgan (National Institutes of Health, Bethesda, MD) (Figure 2). The pGCEN neo retroviral vector expresses an inserted gene from the Moloney murine leukemia virus Long Terminal Repeat (LTR). An IRES sequence allows the expression of the neomycin resistance gene from the same promoter (Boris-Lawrie and Temin, 1993). The sense and antisense Cripto cDNA clones containing full length murine $\mathrm{Cr}-1$ coding sequence was inserted into the Xhol site of the polylinker region in both sense and antisense orientations. PA317 producer cells (Miller and Buttimore, 1986) were transfected with $20 \mu \mathrm{g}$ vector coprecipitated with calcium phosphate. Positive clones were selected with $800 \mu \mathrm{g} / \mathrm{ml} \mathrm{G} 418$ after 5 days in culture. Supernatants free of G418 were collected and used immediately or aliquoted and stored at $-70^{\circ} \mathrm{C}$.

The CID 9 cells were infected with retroviral supernatant containing $\mathrm{Cr}-1$ either in the sense or antisense orientation or the empty vector. The cells were plated at $8 \times 10^{5}$ cells per $100 \mathrm{~cm}^{2}$ dish and the next day fed with $8 \mathrm{ml}$ of viral supernatant (prefiltered through a $0.45 \mathrm{~mm}$ filter), $8 \mathrm{ml} \mathrm{Hams}$ F12 media, $4 \mu \mathrm{g} / \mathrm{ml}$ polybrene and $5 \mu \mathrm{g} / \mathrm{ml}$ insulin. After $24 \mathrm{~h}$ the infected cells were selected using G418 $(400 \mu \mathrm{g} / \mathrm{ml})$ in the media. Greater than 250 colonies were pooled and used in the studies as a mixed population. Because both $\mathrm{Cr}-1$ sense and antisense sequences and the selectable marker neo are expressed from a single promoter using this vector, the cells were tested every few passages to determine that they maintained G418 resistance and hence Cripto expression.

\section{Expression analysis}

Mammary protein was obtained from mammary glands of staged mice. The tissues were homogenized in hypotonic buffer $(20 \mathrm{mM}$ HEPES, pH 7.4; 1 mM EDTA; 1 mM MgCl $; 1 \mu \mathrm{g} / \mathrm{ml}$ phenylmethylsulfonyl fluoride; $20 \mu \mathrm{g} / \mathrm{ml}$ aprotinin) and solubilized in sample buffer (Laemmli, 1970). Culture dishes were washed twice in phosphate buffered saline (PBS) and lysed in sample buffer. Cells grown on the extracellular matrix were first treated with dispase (Collaborative Biomedical Products, Bedford, MA) for $1 \mathrm{~h}$ to dissolve the matrix and then washed and lysed as above. Equal amounts of protein were electrophoresed on a 15\% SDS-PAGE gel and electrotransfered to Immobilon membranes (Millipore Corporation, Bedford, $\mathrm{MA})$. Western blot analysis was performed and visualized using the ECL detection system (Amersham Corp., Little Chalfont, UK). Indirect immunofluorescence assays were done on fixed cell monolayers using monoclonal antibodies to pan-keratin or vimentin (Sigma Chemical Corp., St Louis, MO) with FITC-labeled rabbit anti mouse Ig as secondary antibodies. 
The rabbit polyclonal antibody was raised against a murine Cripto peptide, amino acid sequence 26 to 39 , RDLAIRDNSIWDQK. The antimouse milk serum was a generous gift from Dr N Hynes (Friedrich Miescher Institute, Basel Switzerland). This antiserum recognizes several milk protein including $\beta$-casein and the $22 \mathrm{kDa}$ protein (Marte et al, 1995b). Sheep anti-mouse casein antibody was kindly supplied by $\operatorname{Dr} B$ Vonderhaar $(\mathrm{NCl})$. A rabbit polyclonal antibody to rat $\alpha$-actinin was a gift from Dr J Singer (UC San Diego, CA) and served as a control for equal protein loading on the gel.

\section{Mammary fat pad transplants}

Mice were anesthetized with avertin. Mammary gland 'clearing' was performed on the right inguinal \#4 fat pads of mice at 3 to 4 weeks of age as described previously (Deome et al, 1959; Faulkin and Deome, 1960). In essence, the nipple and primitive adjacent mammary epithelial tissue were excised while the remaining fat pad provided the region for growth of transplanted cells. The CID 9 cells were washed in serum-free medium and injected into the fat pads at approximately $1 \times 10^{5}$ cells per fat pad in 5 to $10 \mu$ l volumes (Edwards et al, 1988). The skin was sutured, and mice maintained for 6 weeks to allow the transplanted cells to grow in the fat pad. Glands or tissues were dissected out, divided into portions and frozen for later analysis.

\section{Acknowledgements}

This research was supported by funds provided by the PHS 5T 32 CA 09579 and by the Breast Cancer Fund of the State of California through the Breast Cancer Research Program of the University of California, Grant Number 1FB-0064 (CCN). Support is gratefully acknowledged from the USAMRMC, grant number DAMD17-94-J-4286 (EDA) and from the Italian Association for Cancer (AIRC) (MGP). We thank our colleagues for positive criticisms and encouragement. We received generous gifts from Drs. N Hynes, B Vonderhaar, M Bissell, D Medina, and R Morgan.

\section{References}

Aguilar-Cordova E, Strange R, Young LJ, Billy HT, Gumerlock PH and Cardiff RD (1991) Viral Ha-ras mediated mammary tumor progression. Oncogene 6: 1601 1607

Baldassarre G, Romano A, Armenante F, Rambaldi M, Paoletti I, Sandomenico C, Pepe S, Staibano S, Salvatore G, Derosa G, Persico MG and Viglietto G (1997) Expression of Teratocarcinoma-Derived Growth Factor-1 (Tdfg-1) In Testis Germ Cell Tumors and Its Effects On Growth and Differentiation of Embryonal Carcinoma Cell Line Ntera2/D1. Oncogene 15: 927-936

Boris-Lawrie KA and Temin HM (1993) Recent advances in retrovirus vector technology. Current Opinion in Genetics and Development 3: 102-109

Bradbury JM, Sykes H and Edwards PAW (1991) Induction of mouse mammary tumours in a transplantation system by the sequential introduction of the myc and ras oncogenes. Int. J. Cancer 48: 908-915

Brandt R, Normanno N, Gullick WJ, Lin J-H, Harkins R, Scheider D, Jones B-W, Ciardiello F, Persico MG, Armenante F, Kim N and Salomon DS (1994) Identification and biological characterization of an Epidermal Growth Factorrelated protein: Cripto-1. J. Biol. Chem. 269: 17320-17328

Ciardiello F, Dono R, Kim N, Persico MG and Salomon DS (1991) Overexpression of cripto, a novel gene of the epidermal growth factor family, leads to in vitro transformation of a normal mouse mammary epithelial cell line. Cancer Res. 51: $1051-1054$

Ciccodicola A, Dono R, ObiciS, Simeone A, Zollo Mand Persico MG (1989) Molecular characterization of a gene of the 'EGF family' expressed in undifferentiated human NTERA2 teratocarcinoma cells. EMBO J. 8: 1987-1991

Coleman S and Daniel CW (1990) Inhibition of mouse mammary ductal morphogenesis and down-regulation of the EGF receptor by epidermal growth factor. Dev. Biol. 137: 425-433
Danielson KG, Obern CJ, Durban EM, ButelJS and Medina D (1984) Epithelial mouse mammary cell line exhibiting normal morphogenesis in vivo and functional differentiation in vitro. Proc. Natl. Acad. Sci. USA. 81: 3756-3760

Deome KB, Faulkin LJJ, Bern HA and Blair PB (1959) Development of mammary tumors from hyperplastic alveolar nodules transplanted into gland-free mammary fat pads of female $\mathrm{C} 3 \mathrm{H}$ mice. Canc. Res. 19: 515-525

Desprez P-Y, Roskeley C, Campisi J and Bissell MJ (1993) Isolation of functional cell lines from a mouse mammary epithelial cell strain: the importance of basement membrane and cell-cell interaction. Mol. Cell. Differ. 1: 99-110

Dono R, Montuori N, Rocchi M, De Ponti-Zilli L, Ciccodicola A and Persico MG (1991) Isolation and characterization of the CRIPTO autosomal gene and its X-linked related sequence. Amer. J. Hum. Genet. 49: 555-565

Dono R, Scalera L, Pacifico F, Acampora D, Persico MG and Simeone A (1993) The murine cripto gene: expression during mesoderm induction and early heart morphogenesis. Development 118: 1157-1168

Edwards PAW, Ward JL and Bradbury JM (1988) Alteration of morphogenesis by the v-myc oncogene in transplants of mammary gland. Oncogene 2: 407-412

Faulkin LJ Jr and Deome KB (1960) Regulation of growth and spacing of gland elements in the mammary fat pad of the C3H mouse. J. Natl. Canc. Inst. 24: 953963

Ghattas IR, Sanes JR and Majors JE (1991) The encephalomyocarditis virus internal ribosome entry site allows efficient coexpression of two genes from a recombinant provirus in cultured cells and in embryos. Mol. Cell. Biol. 11: $5848-5859$

Kannan S, De Santis M, Lohmeyer M, Riese Djn, Smith GH, Hynes N, Seno M, Brandt R, Bianco C, Persico G, Kenney N, Normanno N, Martinez-Lacaci I, Ciardiello F, Stern DF, Gullick WJ and Salomon DS (1997) Cripto enhances the tyrosine phosphorylation of Shc and activates mitogen-activated protein kinase (MAPK) in mammary epithelial cells. J. Biol. Chem. 272: 3330-3335

Kenney NJ, Huang RP, Johnson GR, Wu JX, Okamura D, Matheny W, Kordon E, Gullick WJ, Plowman G, Smith GH and et al. (1995) Detection and location of amphiregulin and Cripto-1 expression in the developing postnatal mouse mammary gland. Mol. Reprod. Dev. 41: 277-286

Kenney NJ, Saeki T, Gottardis M, Kim N, Garcia-Morales P, Martin MB, Normanno N, Ciardiello F, Day A, CutlerML and etal. (1993) Expression of transforming growth factor alpha antisense mRNA inhibits the estrogen-induced production of TGF alpha and estrogen-induced proliferation of estrogen-responsive human breast cancer cells. J. Cell Physiol. 156: 497-514

Kinoshita N, Minshull J and Kirschner MW (1995) The identification of two novel ligands of the FGF receptor by a yeast screening method and their activity in Xenopus development. Cell 83: 621-630

LaemmliUK (1970) Cleavage of structural proteins during the assembly of the head of bacteriophage T4. Nature 227: 680-685

Liguori G, Tucci M, Montuori N, Dono R, Lago CT, Pacifico F, Armenante F and Persico MG (1996) Characterization of the mouse Tdgf1 gene and Tdgf pseudogenes. Mamm. Genome. 7: 344-348

Marte BM, Graus-Porta D, Jeschke M, Fabbro D, Hynes NE and Taverna D (1995a) NDF/heregulin activates MAP kinase and p70/p85 S6 kinase during proliferation or differentiation of mammary epithelial cells. Oncogene 10: 167-175

Marte BM, Jeschke M, Graus-Porta D, Taverna D, Hofer P, Groner B, Yarden Y and Hynes NE (1995b) Neu differentiation factor/heregulin modulates growth and differentiation of HC11 mammary epithelial cells. Mol. Endocrinol. 9: 14-23

Martinez-Lacaci I, Saceda M, Plowman GD, Johnson GR, Normanno N, Salomon DS and Dickson RB (1995) Estrogen and phorbol esters regulate amphiregulin expression by two separate mechanisms in human breast cancer cell lines. Endocrinology. 136: 3983-3992

Miller AD and Buttimore C (1986) Redesign of retrovirus packaging cell lines to avoid recombination leading to helper virus production. Mol. Cell. Biol. 6: 2895-2902

Nandi S (1958) Endocrine control of mammary gland development and function in $\mathrm{C} 3 \mathrm{H} / \mathrm{He} \mathrm{Crgl} \mathrm{mouse.} \mathrm{J.} \mathrm{Natl.} \mathrm{Cancer} \mathrm{Inst.} \mathrm{21:} \mathrm{1039-1063}$

Normanno N, Ciardiello F, BrandtRand Salomon DS (1994) Epidermal growth factorrelated peptides in the pathogenesis of human breast cancer. Breast Cancer Res. Treat. 29: 11-27

Qi CF, Liscia DS, Normanno N, Merlo G, Johnson GR, Gullick WJ, Ciardiello F, Saeki T, Brandt R, Kim N and et al. (1994) Expression of transforming growth factor alpha, amphiregulin and cripto-1 in human breast carcinomas. Br. J. Cancer 69: 903-910 
Reddy KB, Yee D, Hilsenbeck SG, Coffey RJ and Osborne CK (1994) Inhibition of estrogen-induced breast cancer cell proliferation by reduction in autocrine transforming growth factor alpha expression. Cell Growth Differ. 5: 1275-1282

Saccone S, Rapisarda A, Motta S, Dono R, Persico GM, Della Valle G (1995) Regional localization of the human EGF-like growth factor CRIPTO gene (TDGF1) to chromosome 3p21. Hum. Genet. 95: 229-230

Schmidhauser C, Bissell MJ, Myers CA and Casperson GF (1990) Extracellular matrix and hormones transcriptionally regulate bovine beta-casein 5 ' sequences in stably transfected mouse mammary cells. Proc. Natl. Acad. Sci. USA. 87: 9118-9122

Shen MM, Wang H and Leder P (1997) A differential display strategy identifies Cryptic, a novel EGF-related gene expressed in the axial and lateral mesoderm during mouse gastrulation. Development 124: 429-442
Snedeker SM, Brown CF and DiAugustine RP (1991) Expression and functional properties of transforming growth factor a and epidermal growth factor during mouse mammary gland ductal morphogenesis. Proc. Natl. Acad. Sci. USA. 88: $276-280$

Stoker M, O'Neill C, Berryman S and Waxman V (1968) Anchorage and growth regulation in normal and virus-transformed cells. Int. J. Cancer 3: 683-693

Strange R, Friis RR, Bemis LT and Geske FJ (1995) Programmed cell death during mammary gland involution. Methods Cell Biol. 46: 355-368

Streuli CH, Schmidhauser C, Bailey N, Yurchenco P, Skubitz AP, Roskelley C and Bissell MJ (1995) Laminin mediates tissue-specific gene expression in mammary epithelia. J. Cell Biol. 129: 591-603 